\title{
Changes in Mortality in Top 10 Causes of Death from 2011 to 2018
}

J Gen Intern Med 36(8):2517-8

DOI: $10.1007 / \mathrm{s} 11606-020-06070-\mathrm{Z}$

(C) Society of General Internal Medicine 2020

\section{INTRODUCTION}

Trends in mortality rates due to leading causes of death reflect the medical, psychosocial, and economic well-being of a society, and a historical snapshot of such trends can help inform policies of the future. Therefore, we examined changes in the number of deaths and age-adjusted mortality rates (AAMR) attributed to the top 10 causes of death between 2011 and 2018, the last year we have data available from the Centers for Disease Control and Prevention. We chose 2011 as the start date because of earlier work showing a transition in 2011 in 2 of the top 10 causes of death (heart disease and stroke) from a long-term decline to increasing numbers of deaths since then. ${ }^{1}$

\section{METHODS}

The Centers for Disease Control and Prevention WideRanging Online Data for Epidemiologic Research (CDC WONDER) dataset was used to identify national changes in the number of deaths and AAMR due to the top 10 underlying causes of death from January 1, 2011, to December 31, 2018. ${ }^{2}$ The population projection was obtained from U.S. Census data. $^{3}$

\section{RESULTS}

As of 2018, the top 3 causes of death were heart disease, cancer, and accidents (Table 1). The largest percentage decline for AAMR occurred for cancer deaths $(-11.8 \%)$, and the greatest increase in AAMR occurred for deaths due to Alzheimer disease $(+23.5 \%)$. AAMR for influenza and pneumonia $(-5.1 \%)$ and chronic lower respiratory diseases $(-6.6 \%)$ declined. Increases in AAMR due to accidental deaths (+ $22.8 \%)$ and intentional self-harm (suicide) $(+15.4 \%)$ were observed.

Received May 6, 2020

Accepted July 15, 2020

Published online July 23, 2020
Even though the AAMR declined for 7 of the 10 top causes of death, the number of deaths increased for all 10 of the leading causes. This is because the older (age $\geq 65$ years) age group grew at a much more rapid rate than that of the younger (age $<65$ years) $(26.7 \%$ vs. $1.7 \%$ ), while $70 \%$ or more of the deaths from 8 of these causes were concentrated in older (age $\geq 65$ years) adults (Table 2 ).

\section{DISCUSSION}

Important patterns of change in AAMR in the past decade have been previously noted, from stalling of the decline in mortality due to heart disease ${ }^{1}$ to decrease in life expectancy attributed to drug overdoses and suicides among young and middle-aged adults. ${ }^{4}$ While interventions to prevent and treat coronary heart disease (CHD) have been successful, with ageadjusted mortality rate decrease $14.9 \%$ in last decade, the worrisome plateau in the decline in heart disease mortality seems to be driven by an increase in mortality for heart failure $(20.7 \%)$, with majority of deaths due to heart disease happening in the increasing aging population. ${ }^{5}$

The largest percent decline during this time period of the study was noted for cancers. According to a recent report, this progress is driven by long-term declines in death rates for the 4 leading cancers, namely lung, colorectal, breast, and prostate cancers. That report also noted that over 2008-2017, reductions slowed for female breast and colorectal cancers and stopped for prostate cancer; in contrast, declines accelerated for lung cancer, which remains the biggest contributor of mortality among cancers. ${ }^{6}$

It remains to be seen what the final death toll will be due to COVID-19 in 2020. With more than 90,000 deaths by May, it has already surpassed the number of deaths attributed to all but the 6 of the leading causes of deaths in 2018 including influenza and pneumonia, the 8th highest cause of mortality in 2018. Due to the direct and myriad of indirect consequences of this pandemic, mortality rankings due to top 10 causes noted in the current report may look very different in 2020.

As noted, almost three-quarters of the deaths from 8 of these causes were concentrated in older (age $\geq 65$ years) adults. Further, the $\geq 65$ years population is projected to increase by $39 \%$ from 52.4 million in 2018 to 73.1 million in $2030^{3}$ so that the number of deaths from most of the 10 leading causes can be expected to increase unless more effective preventive and therapeutic interventions can be implemented. 
Table 1 Changes in Mortality Attributed to the Top 10 Causes of Death in the USA, 2011-2018

\begin{tabular}{|c|c|c|c|c|c|c|c|c|}
\hline & \multicolumn{4}{|c|}{ Total deaths } & \multicolumn{4}{|c|}{$\begin{array}{l}\text { Age-adjusted mortality rate (per } 100,000 \\
\text { population) }\end{array}$} \\
\hline & 2011 & 2018 & $\begin{array}{l}\text { Absolute } \\
\text { change, } N\end{array}$ & $\begin{array}{l}\text { Percent } \\
\text { change }(\%)\end{array}$ & 2011 & 2018 & $\begin{array}{l}\text { Absolute } \\
\text { change in } \\
\text { AAMR }\end{array}$ & $\begin{array}{l}\text { Percent change } \\
\text { in AAMR }(\%)\end{array}$ \\
\hline $\begin{array}{l}\text { 1. Heart disease (I00-I09, I11, I13, } \\
\text { I20-I51) }\end{array}$ & 596,577 & 655,381 & $+58,804$ & +9.9 & 173.7 & 163.6 & -10.1 & -5.8 \\
\hline 2. Cancer $(\mathrm{C} 00-\mathrm{C} 97)$ & 576,691 & 599,274 & $+22,583$ & +3.9 & 169.0 & 149.1 & -19.9 & -11.8 \\
\hline 3. Accidents (V01-X59, Y85-Y86) & 126,438 & 167,127 & $+40,689$ & +32.2 & 39.1 & 48.0 & +8.9 & +22.8 \\
\hline $\begin{array}{l}\text { 4. Chronic lower respiratory diseases } \\
\text { (J40-J47) }\end{array}$ & 142,943 & 159,486 & $+16,543$ & +11.6 & 42.5 & 39.7 & -2.8 & -6.6 \\
\hline $\begin{array}{l}\text { 5. Cerebrovascular diseases (I60- } \\
\text { I69) }\end{array}$ & 128,932 & 147,810 & $+18,878$ & +14.6 & 37.9 & 37.1 & -0.8 & -2.1 \\
\hline 6. Alzheimer disease (G30) & 84,974 & 122,019 & $+37,045$ & 43.6 & 24.7 & 30.5 & +5.8 & +23.5 \\
\hline 7. Diabetes mellitus (E10-E14) & 73,831 & 84,946 & $+11,115$ & +15.1 & 21.6 & 21.4 & -0.2 & -0.9 \\
\hline $\begin{array}{l}\text { 8. Influenza and pneumonia (J09- } \\
\text { J18) }\end{array}$ & 53,826 & 59,120 & +5294 & +9.8 & 15.7 & 14.9 & -0.8 & -5.1 \\
\hline $\begin{array}{l}\text { 9. Nephritis, nephrotic syndrome } \\
\text { and nephrosis (N00-N07, N17- } \\
\text { N19, N25-27) }\end{array}$ & 45,591 & 51,386 & +5795 & +12.7 & 13.4 & 12.9 & -0.5 & -3.7 \\
\hline $\begin{array}{l}\text { 10. Intentional self-harm (suicide) } \\
\text { (U03, X60-X84, Y87.0) }\end{array}$ & 39,518 & 48,344 & +8826 & +22.3 & 12.3 & 14.2 & +1.9 & +15.4 \\
\hline
\end{tabular}

Table 2 Number of Deaths, Age $\geq 65$ Years, and Percentage of All Deaths, 2018

\begin{tabular}{lll}
\hline \hline & $\begin{array}{l}\text { Number of } \\
\text { deaths }\end{array}$ & $\begin{array}{l}\text { \% of all } \\
\text { deaths }\end{array}$ \\
\hline Heart disease & 526,509 & 80.3 \\
Cancer & 431,102 & 71.9 \\
Accidents & 57,213 & 34.2 \\
Chronic lower respiratory disease & 135,560 & 85.0 \\
Cerebrovascular disease & 127,244 & 86.1 \\
Alzheimer's disease & 120,658 & 98.9 \\
Diabetes mellitus & 60,182 & 70.8 \\
Influenza and pneumonia & 48,888 & 82.7 \\
Nephritis, nephrotic syndrome, and & 42,232 & 82.2 \\
nephrosis & & \\
Intentional self-harm (suicide) & 9147 & 18.9 \\
\hline
\end{tabular}

With approximately 600,000 and more annual deaths due to each, cancer and heart disease, they are likely to remain the top 2 causes respectively, and a sobering reminder that long-term societal challenge of these non-communicable diseases remains.

Jamal S. Rana, MD, PhD, FACC ${ }^{1,2,3}$

Sadiya S. Khan, $M D, M S c^{4,5}$

Donald M. Lloyd-Jones, MD, ScM ${ }^{4,5}$

Stephen Sidney, $M D, M P H^{2}$

${ }^{1}$ Department of Cardiology, The Permanent Medical Group, Kaiser Permanente Northern California,

3600 Broadway, Oakland, CA 94611, USA

${ }^{2}$ Division of Research, Kaiser Permanente Northern California,

Oakland, CA, USA

${ }^{3}$ Department of Medicine, University of California San Francisco,

San Francisco, CA, USA

${ }^{4}$ Department of Preventive Medicine, Northwestern University Feinberg School of Medicine,

Chicago, IL, USA
${ }^{5}$ Division of Cardiology, Department of Medicine, Northwestern University Feinberg School of Medicine,

Chicago, IL, USA

Corresponding Author: Jamal S. Rana, MD, PhD, FACC; Department of Cardiology, The Permanent Medical Group, Kaiser Permanente Northern California, 3600 Broadway, Oakland, CA 94611, USA (e-mail: jamal.s.rana@kp.org).

\section{Compliance with Ethical Standards:}

Conflict of Interest: The authors declare that they do not have a conflict of interest.

\section{REFERENCES}

1. Sidney S, Quesenberry CP Jr., Jaffe MG, et al. Recent trends in cardiovascular mortality in the United States and public health goals. JAMA Cardiol. 2016;1(5):594-599.

2. Centers for Disease Control and Prevention, National Center for Health Statistics. Underlying cause of death, 1999-2017. CDC WONDER [database online]. Atlanta, GA: Centers for Disease Control and Prevention; 2018. https://wonder.cdc.gov/ucd-icd10.html. Accessed Apr 15, 2020.

3. U.S. Census. 2017 National Population Projections Tables: Main Series. Projected Age and Sex Distribution of the Population. Table 2, https:// www.census.gov/data/tables/2017/demo/popproj/2017-summarytables.html, accessed May 17, 2020.

4. Woolf SH, Schoomaker H. Life Expectancy and Mortality Rates in the United States, 1959-2017. JAMA. 2019;322(20):1996-2016.

5. Sidney S, Go AS, Jaffe MG, Solomon MD, Ambrosy AP, Rana JS. Association Between Aging of the US Population and Heart Disease Mortality From 2011 to 2017. JAMA Cardiol. 2019. https://doi.org/10. 1001/jamacardio.2019.4187. [Epub ahead of print].

6. Siegel RL, Miller KD, Jemal A. Cancer statistics, 2020. CA Cancer J Clin. 2020;70(1):7-30.

Publisher's Note: Springer Nature remains neutral with regard to jurisdictional claims in published maps and institutional affiliations. 